\title{
An Analytical Review of Sustainable Green Buildings in Qatar: Implementations in the Architecture, Engineering and Construction (AEC) Sector
}

\author{
Diala Al Midani \\ dalmidani@qu.edu.qa \\ Department of Architecture and Urban Planning, Qatar University, Doha, Qatar \\ Fodil Fadli \\ f.fadli@qu.edu.qa \\ Department of Architecture and Urban Planning, Qatar University, Doha, Qatar
}

\begin{abstract}
Sustainable buildings and related construction techniques are becoming increasingly recognized within the urban planning development in Qatar. The study aims to develop an analytical review of sustainable green projects in several countries to highlight the main sustainable green buildings principles and techniques. In addition, the study aims to propose a set of recommendations that facilitate and improve the green building principles implementation in Qatar. The methodology is based on qualitative approach in collecting data about the sustainable green buildings besides highlighting existing relevant projects from different countries. Moreover, analyzing the green building assessments systems to review their classification and technique. The analysis reveals that sustainability is witnessing a growing awareness in the construction domain in Qatar and many countries, which is leading to a prominent attention to develop green buildings and sustainable construction industries. The discussion indicates some perplexed opinions related to green buildings issues, such as the cost. Therefore, the present paper mentions that green building approaches still need further knowledge across stakeholders to demonstrate the various benefits of green buildings, primarily the energy efficiency to promote best practices. Consequently, the paper addresses the need for a governmental legislation to ensure implementing green buildings as a step forward on sustainability implementation in the AEC (Architecture, Engineering and Construction) sector in Qatar.
\end{abstract}

Keywords: Green buildings; Sustainability; AEC sector; Qatar

\section{INTRODUCTION}

Sustainable Green Buildings are one of the most effective construction techniques that is used in the world. It is widely used in the last few years in some Arab countries, especially in Qatar and United Arab Emirates (UAE). It is becoming more common because of its outstanding efficiency in consuming the resources such as energy and water supplies. It, also, uses environment friendly construction materials that produce less amount of carbon dioxide. The construction technique of sustainable green buildings includes the design, implementation, operation, removal and recycling of the building materials and it takes into consideration the basics of environment friendly construction in each phase. It has the least effect on the surrounding environment compared to regular buildings. Using this construction technique has helped the Qatari government's plan to ensure saving the power resources by $50 \%$ and the water usage by $40 \%$. The construction 
materials used in green buildings helped reducing the harmful emissions by $35 \%$ (Schulz, 2018). All of the previous gives a good explanation why the international market of green buildings is expected to grow from 7 billion $\$$ in 2015 to be 36 billion $\$$ in 2020 (Waked, 2018). The Qatari government is paying more attention and doing serious studies in the field of sustainable construction and green buildings as it is adopting that technique in its future construction projects. The GSAS (Global Sustainability Assessment System) was developed in association with the Pennsylvanian University to create a sustainable urban environment that reduces the environmental impact of the buildings. The spread of the implementations of the sustainable construction in Qatar is benefiting the environment as it reduces the consumption and produces less air pollution. This spread helps to make a high standard building with a great architectural design, which in return creates the modern urban environments. (X.L. Zhao, 2016).

There is a split in opinions of whether the sustainable green buildings construction technique is very effective. The pretense was that this technique costs a lot of money compared to the regular types of buildings. It is, indeed, much more expensive than regular types of construction, but we should also consider how much of the resources consumption it reduces, and then, we could tell how efficient it is.

In this study three existing examples of sustainable green buildings from different countries has been highlighted in order to produce a comprehensive and analytical review of the sustainable green building's technique.

The objective of this study is to determine the effect of sustainable construction on the AEC sector in Qatar, the neutralization of the relationship between the cost of sustainable green buildings and the saving in the resources consumption and finally how the implementations of that technique in Qatar is being subdued to an accredited system or code of specifications.

\section{BACKGROUND}

Sustainable green buildings technique is considered a visionary trend that sooner or later many countries will adopt. This technique was developed gradually over many years. In the engineering fields, the ideas are generated from problems, that is how the sustainable construction technique started. There was a persistent need to solve problems such as the increasing demand and consumption of the resources like energy and water. The studies mentioned that the regular building materials are responsible for a huge amount of the carbon dioxide generated in the air (Meadows, 2010). Then the idea of finding an alternative techniques and materials was developed to mitigate these problems. The cost is much more expensive than usual, but the results was significantly positive.

The following are some examples of the implementations of the sustainable green buildings and a brief review of each one:

\subsection{BedZED:}

The Beddington Zero Energy Development (BedZED) is a great existing example of sustainable construction implementations. It is an environmentally friendly housing development that is located in England, in Hackbridge, London. It was the first large scale community in the United Kingdom. The project started in 2000 and it was completed in 2002. The project belongs to Peabody Group which has more than 66000 homes in London 
Peabody Group made partnership with architect Bill Dunster in order to carry out the project of building the first large-scale community in the United Kingdom. The building was designed to be carbon neutral by creating zero carbon dioxide emission, which helps being an environmentally friendly building. BedZED project is also distinguished by being the first construction project where the government of the United Kingdom sold the land at a lower price than the market in order to encourage sustainable development economically viable. The BedZED project consists of 82 homes and about 1405 square meters of workspace.

In order to be a zero-carbon emission facility, private transportation is discouraged. The project encourages public transportation (like the provided rail and bus routes), cycling and walking beside having a very limited parking space. BedZED project's buildings uses only renewable energy resources which is generated on site. The main source of energy is the 777 square meters of solar panels. There are many systems that provide different forms of energy such as Cogeneration or Combined Heat and Power (CHP) system, which is fueled by the tree waste to provide electricity. Everything was taken into consideration while the construction process, even the building materials were selected from renewable or recycled sources. The materials were selected within maximum 50 miles around the construction site in order to minimize the required energy for transportation. The architectural design stated that the houses were oriented to face the southern direction so that it faces the sun most of the day and have the maximum possible thermal insulation. The water system also was selected to rely on the rainwater, which is collected and treated to be reused, and the recycled water. In the terms of the urban appearance, the apartments finishing was done to a high standard to satisfy the residents. Private cars were discouraged while public transportation and walking were encouraged. (Peabody, n.d.)

One year after the start of the operation, the project achieved distinguished records as an environmentally friendly project. The space heating was not as much needed as usual. More than the half reduced the hot water consumption. The use of electricity was also, reduced thanks to the smart systems and the solar power panels. Special vehicles had less mileage than usual as planned after encouraging using public transportation, cycling and walking. The cost of the apartments in the project is very expensive hoping that would change in the near future. A while after the start of the operation, a few problems were found such as the dysfunctional problems in many of the systems used to generate electricity and to recycle the water. The maintenance costs a lot of money and that made the problem harder to cure. (Peabody, n.d.)

BedZED project was a significant example of the sustainable construction and green buildings. It gained many awards from 2000 till 2005 such as: Housing Design Award for sustainability from the Royal Institute of British Architects in 2001 - Evening Standard New Homes Awards in 2001 - Office of the Deputy Prime Minister Award for sustainable communities in 2003 - Stirling Prize in 2003 - Bremen Awards Special Commendation in 2004 - Sutton and Cheam Society Design award in 2005.

\subsection{Chorlton Park Apartments:}

The Chorlton Park Apartments is a green apartment building, in England. It was designed by Roger Stephenson, an architect, and built as part of collaboration between 
Urban Splash and Irwell Valley in the year 2002. The project collected several awards such as the Housing Design Award in 2001, Roses Design Awards - best residential project in 2002 and in 2003 in the residential section; it won the MSA Design Award as well. (Colquhoun, 1999)

Natural light is maximized by the orientation of its living rooms with bedrooms located on the inner side of the building to have the minimum noise from the street. Each apartment has a balcony with louvered screens on rollers to provide shade and privacy. They are designed to be an extension of the living space and are constructed using a frame of green-oak posts and beams which were reclaimed from a wind-damaged forest in France. The standards of the green buildings were considered while the phases of the design, implementation and operation of the facilities of the project. Low heating and maintenance costs and sustainable construction were among the priorities in developing the site.

\subsection{Green Building Principles:}

There are some principles that the green buildings should have in the terms of design, implementation, operation and recycling. These principles are considered the most important as they are the elements that make a green building. (Seville, 2013)

- Zero Energy: The design of the project considered that only energy from renewable sources generated on site or near the construction site will be user. Usual types of energy like gas that runs cars are not encouraged because of the environment harmful gases it causes. Also, energy resources need transportation and that idea is not encouraged, in order to minimize the harmful gases in the site area.

- Energy Smart: the house is preferred to face the sun most of the time if it's possible, to help the solar panels absorb the sunlight and produce clean energy. The houses also have the most thermal insulation, so facing the sun most of the time is not considering a problem.

-Water Efficient: the water used in the projects of green building is not relying on the regular resources of water, it uses the rainwater which is collected after the rain and used. Also, the reclaimed water is used since the projects have water recycling units.

- Low-Impact Materials: The building materials are selected from renewable sources or recycled ones. It is preferred to collect building materials within $80 \mathrm{~km}$ from the construction site, to minimize the energy required for transportation.

-Waste Recycling: Waste is collected in facilities that are designed to support recycling.

- Transportation: Private cars are discouraged in many ways such as awareness campaigns, car free zones in specific areas and by reducing the parking areas. Otherwise, public transportation, cycling and walking are encouraged and supported.

\section{- High Quality of Life.}

These and others are the most common principles of green building construction that every green building design should consider. It delivers a high-quality building that ensures the high class and high standard lifestyles and being an environmentally friendly building (Seville, 2013).

\section{METHODOLOGY}

The study is based on qualitative approach in collecting data about the sustainable 
construction and green buildings. Firstly, it highlights existing sustainable projects from different countries, then analyzing the green building assessments to review the assessment classification and technique. Consequently, addressing certified green and sustainable projects in Qatar and gulf region. The study adopts data from the United Nations Environment Program (UNEP) about the effect of the regular building on the environment, in addition to the statistics from the United States Green Building Council (USGBC) to highlight the importance of the sustainable green buildings system.

The collected data is mainly gathered from certified websites like the United Nations Environmental Program (UNEP) official website, Peabody and IES LTD.

\section{ANALYSIS}

The sustainable green buildings construction is based on some well-known concepts that every building must achieve. The buildings are subjected to the evaluation by one of the international evaluation systems such as LEED or BREEAM. These two systems are examples for the systems that determine whether the building is a green building or not. But at first it is necessary to overview the GSAS and QSAS. They are also green building evaluation systems. In Arab countries, the sustainability of the buildings is greatly required to not only cope with the growing needs of comfort and high standard apartments, but also to respond to the nature whining about how cruel the humanity is dealing with the resources and wasting it. Green buildings may cost more than regular buildings in the implementation phase, but once the building is ready for operation, almost every single resource consumption is reduced by a great percentage. It is called "green" buildings for an obvious reasons, it reduces the harmful effect of the regular buildings on the environment, as in usual the regular buildings are responsible for about $35 \%$ of the carbon produced in the air (Schulz, 2018). The building materials, the public transportation and all other elements of the construction process are taken into a. The GSAS is considered as the most comprehensive green building assessment system in the whole world. It was set after the precise analysis of over 40 green buildings codes of specifications from all over the world. One of the most important advantages of the GSAS is that it considers the social, economic, environmental and cultural features of the society, which mainly differ from one country to another around the world. Many of the Middle Eastern and North African (MENA) countries such as, Saudi Arabia, Kuwait, Jordan and Sudan paid great attention about considering the GSAS a unified green building certification in the MENA region. (Schulz, 2018)

In 2010, Qatar included the Qatar Sustainability Assessment System (QSAS) in Qatar construction code of specifications. Recently every single project whether it is a public or private sector must have a GSAS certificate. The 140 building rating system of GSAS includes a sustainability assessment mechanism and it divides into 8 sections: urban communication, site, energy, water, urban environment, economic value, cultural value management and operation. Every section of the system is measuring a specific criterion of the environmental impact of the project. The sections are well illustrated and clear. The sections of the project are evaluated and given degrees that match comply with the specifications. (Waked, 2018)

The government in Abu Dhabi made an initiative to improve the life of residents in Abu Dhabi throughout concentrating on the cultural habits and the social values, so it 
initiated the Pearl Rating System (PRS). The PRS is Abu Dhabi Emirate green building assessment system. It was designed to support the sustainability of buildings from the beginning in the design phase until the operation including the building and the villas. It states some requirements to evaluate the expected performance of the project from the sustainability perspective. The PRS is made with precision to consider the common climate in Abu Dhabi that requires a high need of energy to satisfy the air conditioning systems, high evaporating rate and low rate of rain flow and lack of drinking water. The PRS has many levels of certifications starting form one pearl reaching up to 5 pearls. To develop any project inside Abu Dhabi Emirate, it is required to have a certificate with at least 1 pearl. The PRS is divided into 7 sections, which are getting between compulsory credits and optional credits. To get the 1 pearl certificate it is required that all the compulsory credits are achieved (Aigbavboa, 2019).

Unlike the GSAS there is a less famous system to rate the green buildings in Lebanon which is called the ARZ Rating System. It is the first Lebanese green building assessment system as an initiative to create an international code of specifications with a credential system managed by Lebanon Green Building Council (LGBC). That council was created to support the implementations of the sustainable green buildings in Lebanon. ARZ Rating System was developed by Lebanese experts from the LGBC in association with the National Finance Corporation. The system aims to achieve the most efficiency in operation and reducing the environmental impact. ARZ Rating System is a curriculum based on evidence to evaluate the sustainability of buildings. The system includes some techniques, procedures and energy-consuming levels that the LGBC expect to see in the future in the Lebanese sustainable green buildings. An evaluator certified by the LGBC performs an inventory of the energy consumption, the water consumption and the procedures and techniques applied in the building, then the LGBC gives a rating degree to the building based on how it is corresponding with the techniques and procedures related to the ARZ Rating System (Islam, 2019).

\subsection{GSAS:}

GSAS refers to the Global Sustainability Assessment System, which is based on performance and developed for rating sustainable green buildings and infrastructures. Its main and primary objective is to create a sustainable environment that minimizes ecological impacts and reduces the consumption of resources, like energy and water, while addressing the local needs and environmental conditions of the region. It adopts an integrated lifecycle approach for the assessment of the environment including the phases of the design, construction and operation (Sillitoe, 2017). The GSAS started in 2007 by reviewing more than 140 building rating systems and codes of specifications, tools, and guidelines from all over the world and narrowed down to the 40 whole building rating systems. The study then focused on the review and the assessment of the best practices adopted by international green buildings rating systems. The system aims to improve the human wellbeing, protecting natural environment and conserving natural resources (GORD, 2019).

\subsection{QSAS:}

It might be said that Qatar Sustainability Assessment System (QSAS) is the Qatari 
specialized Global Sustainability Assessment System. It is a green building certification system developed for the State of Qatar. The primary objective of QSAS is similar to the GSAS objective, which is to create a sustainable environment that minimizes ecological impact while addressing the specific regional needs and environment of Qatar and Qatari people. It was developed in 2010 by the Gulf Organization for Research \& Development (GORD) in association with the University of Pennsylvania to achieve the objective of the GSAS/QSAS to create a sustainable modernized environment to reduce the buildings' ecological impact and in the same time achieving the needs of the society (Sillitoe, 2017).

\subsection{UN Environment Program:}

The United Nations gives strong attention to the sustainability of the environment, the United Nations Environment Program (UNEP) took seriously the issue of sustainable buildings after the increasing rates of pollution and resources consumption. Studies showed a clear relationship between public health and buildings in terms of being harmfully affecting. Meanwhile, the built environment developed based on a huge amount of energy which is about $40 \%$ of the global energy consumption, greenhouse gas (GHG) emissions which is about $30 \%$, the generated waste and natural resources consumption that are threatened to run out (Meadows, 2010).

UNEP started the Sustainable Buildings and Climate Initiative (SBCI) in 2006 in order to address these issues. It supports the practices of sustainable buildings on a wide scale with a focus on the efficiency of energy and emission reduction of Greenhouse Gas (GHG). SBCI gather around stakeholders who are involved in the process of planning, building and policy making on the local, national and international levels by providing a space for discussion and well-studied teamwork decisions. The initiative develops strategies of a better evaluation and implementations of the sustainable building practices. Pilot projects show how important is the role of green buildings for adaptation to different climate changes. Sustainable Social Housing Initiative (SUSHI) is one of those pilot projects in UNEP. It enhances the sustainability in the green social housing projects. Another project to test the available tools and construction strategies is the Sustainable Buildings Policies in Developing Countries (SPOD). It aims to help governments at both of the national and the local fields in order to develop policy tools to support the practices of the green buildings and the mainstreaming sustainable construction. In two pilot cities, Ouagadougou 'Burkina Faso' and Nairobi 'Kenya', a 'Quick Scan Tool' to evaluate the policies in the building branch and also scenarios to improve the state are being tested (Sustainable Buildings, n.d.).

\subsection{Green Building Projects in Qatar and Gulf region}

There are several projects in the Gulf region that adopted the sustainability construction techniques of green buildings. Some of them are in, Qatar and others in Gulf region as the following:

\section{Qatar Museums Authority (QMA) Tower:}

Qatar Museums Authority (QMA) Tower is a Grade (A) 16 floor commercial office buildings in Doha. The building is used as the Qatari Museums Association head office in Qatar. The project managed to achieve the requirements of the LEED Silver Certified 
level of sustainability in construction under the United States Green Building Council's (USGBC), Leadership in Energy and Environmental Design (LEED ${ }^{\mathrm{TM}}$ ) and Green Building Rating System for Commercial Interiors 2009. (Oxford Business Group, 2014) Sowwah Square:

This project is covering an area of 500000 square meters and is located in Abu Dhabi in the United Arab Emirates (UAE). It is a multibillion-dollar project, a mixeduse waterfront development, comprise of four commercial towers ranging from 33 to 36 stories, as well as two buildings with six story car parks and the iconic Abu Dhabi Securities Exchange, alongside a luxury retail and restaurants. It obtained the LEED Gold certification of sustainability in 2014 (Location Group Research, 2014).

\section{Lusail Marina District:}

Lusail Marina District is a 21+ story residential building located in Lusail City, which is one of the most groundbreaking concepts of Qatari Diar Real Estate Investment Company. Lusail City is a futuristic project, which will deliver a modern and ambitious society in Qatar. The smart and inspirational environment combines artistic elements of architecture with various practical and versatile services in order to deliver perfect products that satisfy all the needs of its residents (Oxford Business Group, 2014).

\section{Al Ain Ladies Club:}

The implementation of the project took about 2 years, from 2012 until 2014. The project provides ladies-only sports facility in the City of Al Ain and is part of the Abu Dhabi Sports Council's mission to ensure the provision of such facilities within the Abu Dhabi Emirate. The project has a net floor area of around 13,500 square meters with two floors. It has been designed to achieve a 2-Pearl rating from the PRS (Jane Stark, Trident Press, 2006).

\section{DISCUSSION}

From the previous brief review of opinions and projects related to sustainable green buildings then following it by reviewing existing sustainable projects. It became obvious how important to spread the approach of sustainable construction technique and green buildings. These are, the future of construction around the world. Qatar took that important step forward on the way to achieve its own individuals' prosperity and welfare, also to achieve the criteria of creating a sustainable environment with less harmful building materials, cleaner air and less energy resources consumption. The only problem that may face the projects of sustainable green buildings and sustainable is the cost. It has seen that the cost of a green building shall be divided into smaller sections or categories: Design, implementation, operation, maintenance and recycling. The high cost of green building is just until the implementation phase, and then the cost is less than regular buildings. The cost of the operation, maintenance and recycling is much less than usual as well. Thus, if a financial study were performed, investors would get encouraged to invest their money in the sustainable green building projects as it is not only a lower cost investment, but it is also a money saving investment that could, after few years, generate energy and have renewable resources. In order to ensure spreading this technique in the state of Qatar, the need for a governmental legislation is necessary. Ensure implementing green buildings is a step forward on sustainability implementation in the AEC. The study suggests additional recommendation to enhance the sustainable 
green buildings implementation in Qatar as the following:

a. Expand green building education and awareness by providing educational campaigns.

b. Outreach to the financial and real estate community about the criteria and benefits of Green Building.

c. Continue and expand the professional development opportunities and requirements for staff by providing internal and external training.

d. Involve experts that can guide the project and implementation.

e. Share best practices with other companies/stakeholders.

f. Use water conservation products and practices when building.

g. Practice sustainable storm water management at building sites.

h. Recycling and reusing materials, on and off site.

i. Use local materials as much as possible to reduce transportation needs.

j. Design for the use of disassembly and reuse/recycling.

\section{CONCLUSION}

Finally, it is obvious that the sustainability techniques are important. As shown in the previous background, there are many existing examples of the sustainable green buildings in MENA region, especially in Qatar and United Arab Emirates. The climate state in those countries tempted its governments to think of alternative ways of construction, saving energy resources and deliver the high standard buildings and apartments that are also depend on the renewable energy resources. The sustainable construction satisfied all these needs and gave hope to a sustainable environment. It uses only renewable resources of energy, have special units and solar panels to generate electricity, have units that collect rainwater and recycle the used water, use environmentally friendly building materials that produce less carbon to the air. After a while of using the sustainability construction technique, the statistics from the Press Room of the United States Green Building Council (USGBC) showed that the electricity consumption was reduced by $30 \%$, the hot water consumption is less by $57 \%$, the private cars mileage was less by $65 \%$ and the most important for the environment, the carbon in the air was measured to be less by $40 \%$ in the green building areas (Press: Benefits of green buildings, 2018). Therefore, the study highlights the need of integrating the sustainable green buildings in the AEC sector in Qatar, which are seeking for a sustainable environment. The paper proposes a set of recommendations that contributes to enhance and improve the sustainable green buildings implementation.

\section{REFERENCES}

Aigbavboa, O. D. (2019). Sustainable Design and Construction in Africa: A System Dynamics Approach. New York, Abingdon: Routledge.

Colquhoun, I. (1999). RIBA Book of British Housing. Elsevier.

Fox, W. (2000). Ethics and the Built Environment. London: Routledge.

GORD. (2019). Retrieved from GORD: http://www.gord.qa/trust-gsas-resource-center-overview. Islam, M. N. (2019). Silk Road to Belt Road: Reinventing the Past and Shaping the Future. Springer International. 
Jane Stark \& Trident Press. (2006). United Arab Emirates Yearbook 2006. Trident Press, Ministry of information and technology.

Kalle Kähkönen, J. P. (2005). Global Perspectives on Management and Economics in the AEC Sector. Technical Research Centre of Finland.

Location Group Research (2014). Retail Market Study Worldwide, 2014.

Meadows, R. S. (2010). Green Building Materials: A Guide to Product Selection and Specification. New Jersey: Wiley.

Oxford Business Group (2014). The Report: Qatar 2014.

Peabody.(n.d.). Retrieved from BedZED: https://www.peabody.org.uk/about-us/our-performance/ sustainability/case-study-bedzed.

Press: Benefits of green buildings. (2018, Nov. 13). Retrieved from USGBC: https://www.usgbc. org/articles/green-building-accelerates-around-world-poised-strong-growth-2021.

Schulz, J. A. (2018). Green Building Transitions. Springer International Publishing.

Seville, A. K. (2013). Green Building: Principles and Practices in Residential Construction. Delmar.

Sillitoe, P. (2017). Sustainable Development: An Appraisal from the Gulf Region. New York, Oxford: Berghahn.

Sustainable Buildings. (n.d.). Retrieved from UN Environment Program: https://www. unenvironment.org/explore-topics/resource-efficiency/what-we-do/cities/sustainablebuildings.

Waked, T. (2018, 11 11). نظم تقييم المباني الخضر اء في الثرق الأوسط. Retrieved from EcoMENA: https:// www.ecomena.org/green-rating-mena-ar/.

X. L. Zhao, W. L. (2016, November 7). A Framework for the Integration of Performance Based Design and Life Cycle Assessment to Design Sustainable Structures. SAGE. 